\title{
Discussion on Application of Dance Anatomy in Basic Training Classroom of Chinese Classical Dance
}

\author{
Hui Dong \\ Hubei Engineering University, Xiaogan Hubei, 432000, China
}

\begin{abstract}
Key words: Dance anatomy, China, Classical dance, Basic training course.
\end{abstract}
\begin{abstract}
The application of dance anatomy in basic training classroom teaching of Chinese classical dance provides pertinent basic training guidance for dance learners by studying the function of each tissue and part of the body of dancers, guarantees the scientificalness and effectiveness of basic training classroom teaching of Chinese classical dance and urges dance learners to get more knowledge about dance. Dance learners can have deeper understandings of their own body shape and structure by learning dance anatomy so as to protect themselves better and reduce injury in basic training. This paper explores the form of application of dance anatomy in basic training classroom teaching of Chinese classical dance on the basis of analyzing dance anatomy and Chinese classical dance.
\end{abstract}

\section{Introduction}

Dance learners can protect their body and avoid injury in basic training and other dance training process to the greatest extent only with full mastery of knowledge about body structure in the process of learning dance anatomy. Dance anatomy has emerged based on the demand of dance specialized courses. Dance anatomy not only presents body structure for dance learners, but also allows dance learners to identify the role of each part of body in dance training and guides them to understand the mystery of body so that they can pay special attention to protect their sensitive and vulnerable parts and reduce body injury effectively in dance training process. In addition, the application of dance anatomy also guides dance learners to have adequate understandings of the internal relation between dance and body structure and lay a solid foundation for consolidating their basic skills.

\section{Analysis on dance anatomy}

Just as its name implies, dance anatomy is human anatomy in dance. Human anatomy is a science studying the law of change and development of human body based on normal and healthy human figure and structure. Normal human figure and structure mean that human figure and structure conform to the general law and are body shape possessed by most people. Healthy human figure and structure mean that a person has good physical development, high physical quality and strong build and various physiological functions are normal ${ }^{[1]}$.As an important branch of human anatomy, dance anatomy puts forward effective strategies for improving dance skills of dancers based on normal and healthy human figure and structure by studying functions of body shape and structure of dancers and the relationship between their law of body growth and development and dance training. As constructors of dance career and dance teaching staff, professional teachers of Chinese classical dance should conduct in-depth study on dance anatomy, explore the law of mechanical movement of body structure of dance learners on the basis of identifying the influence of dance training on their body shape and structure and promote significant improvement of the overall level and quality of Chinese classical dance teaching with the knowledge of dance anatomy. In terms of dancing art 
category, dance anatomy not only provides theoretical guidance for basic training practice, but also is a basic theoretical course that must be mastered by dance learners.

\section{Summary of Chinese classical dance and significance of application of dance anatomy}

Chinese classical dance integrates the essence of western ballet and eastern ancient folk dance. It has both of their features as well as its own personality with the development of era. As an important branch in dance system, Chinese classical dance has strong aesthetic nature with its profound historical origin and is perfect integration of ancient folk dance and modern dance. It plays an important role of link in the development history of dance and carries the culture and art of Chinese nation. Certain innovation has been made based on the original motion and content of ancient folk dance. Therefore, it has stronger national cultural factors, more flexible and variable motions and richer contents, thus providing better experience for audiences ${ }^{[2]}$.Studying dance anatomy has profound significance in Chinese classical dance.

The application of dance anatomy in the classroom teaching process of basic training of Chinese classical dance mainly promotes dance learners' identification of each organ and structure and figure of normal body and adequate understanding of the law of mechanical movement of locomotive organ. Meanwhile, dance learners are promoted by teaching to focus on learning relevant theories of muscle work and motion analysis under the premise of mastering relevant knowledge of normal body figure and structure so as to grasp more technical movements of dance on the basis of avoiding body injury and gradually form the ability of comprehensive analysis on dance movement.

\section{Effective application of dance anatomy in classroom teaching process of basic training of Chinese classical dance}

\section{Adhere to the principle of teaching students according to their aptitude and carry out teaching based on actual situation of dance learners}

Under the background of constant development of the era, Chinese classical dance has been reformed correspondingly and integrated the essence of western ballet and traditional Chinese folk dance. High requirements are put forward for physical quality and the flexibility of joints of dancers ${ }^{[3]}$.The application of dance anatomy in classroom teaching process of basic training of Chinese classical dance can urge dance teaching staff to identify physical characteristics of different dance learners and thereby guide dance learners to have deep understanding of their physical features, provide pertinent guidance for them and improve their effect of basic training in the process of teaching guidance. As professional dance teachers lack theoretical support in dance anatomy in traditional classroom teaching process of basic training of Chinese classical dance, they can only carry out teaching with traditional and simple teaching method in teaching practice, which is difficult to fully guarantee the teaching efficiency and quality of basic training of classical dance and adverse to the consolidation of basic dance skills of dance learners. Meanwhile, dance learners often have the sprain of muscle in basic training process without professional guidance of teachers, which imposes certain threat to the health of dance learners. Therefore, teachers can guide dance learners for comprehensive analysis on their physical quality with dance anatomy as theoretical basis, help them establish basic training plan scientifically and reasonably based on their actual situation and promote them for scientific training according to the basic training plan so as to achieve ideal training effect, improve their physical quality and the flexibility of their joints and consolidate their basic dance skills in the classroom teaching process of basic training of Chinese classical dance.

\section{Aid teaching with anatomy knowledge according to contents of basic training course of Chinese classical dance}

Research contents of dance anatomy can mainly be divided into the following parts: first, study body organ and body shape and structure of normal dancers and conduct in-depth study on the law of 
mechanical movement of their locomotive organs. Second, elaborate the influence of basic training of Chinese classical dance on body shape and structure of dancers according to the actual situation of basic training of Chinese classical dance. Third, guide dance learners to strengthen their understanding of basic theories such as muscle work and motion analysis and urge them to develop the ability of comprehensive analysis on dance technical movements through learning under the premise of their mastery of relevant knowledge about normal body shape and structure. Teachers should carry out classroom teaching aided by anatomy knowledge based on contents of training course in the process of basic training of Chinese classical dance.

Training of pointing toes

Training of pointing toes is also called as foot bowing training. In the motion of pointing instep, primary motorial muscles are triceps surae, posterior tibial muscle, long flexor of cheek and toe, peroneus longus and short peroneal of dancers. The combined action of these muscles enables dancers to point their insteps when their shanks are fixed. Opposed muscles of the motion of pointing instep are dancers' tibialis anterior muscle and extensor hallucis longus of cheek and toe. In the training of pointing toes, primary motorial muscles of the motion of pointing toes are long flexor of cheek, short flexor of cheek, long flexor of toe and short flexor of toe. Opposed muscles are dancers' extensor hallucis longus of cheek, brevis extensor muscle of cheek, extensor hallucis longus of toe and brevis extensor muscle of toe.

Training of back bend

Back bend motion is mainly divided into fast back bend and slow back bend. They have significant differences in muscle work nature. Fast back bend motion includes whisking waist and shaking waist. If a dance movement occurs when the pelvis of dance learner is fixed during back bend, his/her upper part of longissimus dorsi, trapezius, latissimus dorsi, rhomboid muscle, rear part of deltoid and shoulder girdle muscle jointly have dynamic restraining work and make shoulder retract, shoulder joint and sternoclavicular joint keep opening outward and thoracic vertebra extend backwards. For great back bend on this basis, pelvis needs to incline backwards and lower part of longissimus dorsi, quadratus lumborum, gluteus maximus, rear part of gluteus medius, rear part of gluteus minimus, biceps femoris muscle, adductor magnus and semimembranosus conduct dynamic restraining work. In the process of slow back bend, back muscles can first conduct dynamic restraining work and make body extend backwards gradually. Attention should be paid that front muscles conduct dynamic restraining work in the process of straightening the body in both fast back bend and slow back bend.

\section{Jete training}

In the process of jete training, in terms of take-off, dance learners should burst and contract primary motorial muscles such as quadriceps femoris, sartorius, triceps surae and tensor fasciae latae when feet are fixed and straighten knees so as to produce a force of foot and leg to the ground and carry out dynamic restraining work, then keep away from the fixed point, make it move to toes, allow muscles with the function of pointing instep and toes such as flexor digitorum longus, musculus tibialis posterior, peroneus longus, short peroneal, short flexor of cheek and short flexor of toes to carry out dynamic restraining work. Under the explosive contraction of these muscles, heel, sole and toes of dance learners will keep away from the ground and therefore, their body will take off.When falling to the ground, short flexor and long flexor of cheek and toes start to carry out concessive work, followed by triceps surae, tibialis posterior and peroneus longus. On this basis, toes, sole and heel of dance learners can gradually fall to the ground. After the completion of these movements, triceps surae, quadriceps femoris, sartorius and tensor fasciae latae continue to keep a concessive state so as to alleviate the bump of body gravity.

\section{Avoid injury in basic training teaching of Chinese classical dance by learning dance anatomy}

In the classroom teaching process of basic training of Chinese classical dance, teachers generally require dance learners to stand with their feet opening outwards, i.e. keep femur turning from acetabulum joint and keep knee joint and tiptoe all open. By standing with feet opening outwards, dance learners can obtain a more favorable area of support, make hip joint have a larger range of 
motion, guarantee more stable body gravity and make all joints adjusting body gravity freer ${ }^{[5]}$.Attention should be paid that pelvis configuration of dance learners has decisive influence on their extent of opening outwards. The motion of opening outwards starts from hip joint of dance learners, transfer Right opening training can not only correct wrong understanding of dance learners, but also allow them to understand that "if weight can not be allocated evenly in the position and gradually 'rolls' to the inner edge of sole from its outer edge, it will cause sole bone to deviate from the normal position and result in injury of feet and knees" at the level of human body motion mechanism around the phenomenon of "false opening of feet". On this basis, dance learners can control their muscles and skeleton reasonably with the knowledge of dance anatomy, reduce the occurrence rate of body injury to the greatest extent through scientific basic training and achieve good training effect.

When dancers keep the posture of bending their knees, it is difficult to guarantee the stability of knee joint especially when dancers are in half bent position with their feet opening outwards. If the opening effect of hip joint of dance learners is not good enough, compensatory opening of their knee joint and ankle joint will cause it difficult for the knee of dance learners to keep in the same direction as their tiptoe direction. Repeated occurrence of such mistake will cause strain of joint ligament of dance learners. Meanwhile, if the force around joints of dance learners is not enough after they take off and fall to the ground, their ability of joint protection will be restrained and their center of gravity will be unstable at the time of falling to the ground, thus causing injury of meniscus. In addition, as inner meniscus and tibial collateral ligaments are connected, the probability of injury of tibial collateral ligaments is seven to ten times of that of meniscus under small range of motion. Therefore, when inner meniscus is injured, tibial collateral ligaments will be injured to different extents.

If dance learners focus on pressing knees in the process of pressing fore leg, it will cause relaxation of oblique ligament and hyperextension of knee. The center of gravity will shift and gradually get close to heel when they are standing, thus influencing the stability of dance learners. For such dance learners, teachers should tell them the correct training method. In the process of pressing fore leg, quadriceps femoris should not put forth strength. Dance learners should focus on stretching posterior muscular group of thigh and lift up quadriceps femoris consciously in the process of standing.

\section{Conclusion}

In conclusion, the application of dance anatomy in training teaching has great significance for dance learners in the classroom teaching process of basic training of Chinese classical dance. According to teaching practice, dance anatomy not only provides scientific basis for the implementation of classroom teaching of basic training of Chinese classical dance, but also promotes the inheritance and development of Chinese classical dance to a certain extent and plays a vital role in dance learning and consolidation of basic skills of Chinese classical dance learners. Therefore, as dance teaching staff and constructors of dance career, teaching staff of Chinese classical dance should be good at using various teaching resources to carry out classroom teaching, use dance anatomy consciously in the classroom teaching process of basic training of Chinese classical dance and promote further inheritance and development of Chinese classical dance.

\section{References}

[1] Li Wei, Ren Fang. Discussions on Characteristics of Basic Skill Training of Chinese Classical Dance, Explorations in Music, 2011(3):131-134.

[2] Zhou Wei. Discussions on Aesthetics, Training and Application of Techniques and Skills of Chinese Classical Dance, Time Education, 2013(12):6-6.

[3] Zheng Jia. Exploration on Relationship between Basic Training and Body Figure Training of Chinese Classical Dance, Theoretical Family, 2015(11):132-132. 
[4] Shi Zhan. Brief Discussion on Training of "Spirit" in Body Figure of Chinese Classical Dance, Music Space Time, 2013(2):91.

[5] Yan Min. Exploration and Analysis on Problems of Basic Skill Training System of Chinese Classical Dance, Art Science and Technology, 2014(8):175-175,177. 